\title{
Improved reservoir characterization by employing hydraulic flow unit classification in one of Iranian carbonate reservoirs
}

\author{
Yousef Rafiei ${ }^{\oplus *}$, Mohadeseh Motie \\ Department of Petroleum Engineering, Amirkabir University of Technology, Tehran, Iran
}

(Received May 22, 2019; revised July 26, 2019; accepted July 28, 2019; available online August 7, 2019)

\section{Citation:}

Rafiei, Y., Motie, M. Improved reservoir characterization by employing hydraulic flow unit classification in one of Iranian carbonate reservoirs. Advances in Geo-Energy Research, 2019, 3(3): 277-286, doi: 10.26804/ager.2019.03.06.

Corresponding author:

*E-mail: y.rafiei@aut.ac.ir

Keywords:

Heterogeneity

hydraulic flow unit

capillary pressure

\begin{abstract}
:
Capillary pressure curves is of great importance in reservoir characterization. Due to the reservoir heterogeneity, no single capillary pressure curve can be used for the entire reservoir depth. This paper aims to examine the application of different techniques of hydraulic flow unit (HFU) classifications in overcoming the extreme heterogeneity of the reservoir in order to improve normalization of capillary pressure in one of the Iranian carbonate oil reservoirs. In this study, well $\log$, routine and specific core analysis lab data have been used to identify flow units by employing different techniques in a heavy oil carbonate reservoir in the south of Iran. These techniques include gamma ray and density log method, flow zone indicator, capillary pressure curves and Winland parameter. Then, mercury injection data has been used by employing Desouky's method to normalize capillary pressure curves for each identified flow unit. According to this study HFU classification significantly improved normalizing of capillary pressure curves.
\end{abstract}

\section{Introduction}

Providing a sufficiently detailed characterization of the overall geological complexity of a reservoir would require a definition of a structural, stratigraphic and a lithological model (Brigaud et al., 2014; Goda et al., 2014; Chang et al., 2015; Hingerl et al., 2016). However, such characterization is proved to be unsatisfactory when the dynamic performance of the field is considered. The geological description should capture the main features related to the fluids flow in the reservoir. Otherwise, reservoir heterogeneity that is regarded as one of the most relevant factors affecting the dynamic behavior of the field, will not be taken into account properly. As known, reservoir heterogeneity is not totally a static issue, and its impacts are strongly related to non-geological parameters, like mobility ratio, PVT properties, and aquifer strength and development strategy (Goda et al., 2014; Pyrcz et al., 2014). Therefore, accurate heterogeneity description seems a critical issue in reservoir studies. Different techniques can be used to identify the presence of reservoir heterogeneity. One of the efficient techniques to address the reservoir heterogeneity in macro scale is hydraulic flow unit (HFU) zonation (Davies et al., 1996; Schatz et al., 2007; Nooruddin et al., 2011; MirzaeiPaiaman et al., 2015).

The concept of flow unit has been developed as an in- tegrating tool for petrophysical description of the reservoir (Stolz et al., 2003; Izadi et al., 2012; Mirzaei-Paiaman et al., 2015, 2018). Based on this concept, rocks with similar petrophysical and flow properties are categorized within the same unit (Pittman, 1992; Amaefule et al., 1993; Soto et al., 2001; Kaydani et al., 2011; Ngo et al., 2015; Rabiller, 2017). Interpretation of flow units based on the petrophysical properties, well log data, and stratigraphy are routinely done for reservoir characterization. As reported by several researchers, this technique provides a better input data set for numerical flow simulation, when compared to those provided by lithological or depositional facies (Chen et al., 1950; Davies et al., 1996; Soto et al., 2001; Bagci et al., 2007; Schatz et al., 2007; Kadkhodaie-Ilkhchi et al., 2009; Nooruddin et al., 2011; Izadi et al., 2012, 2013; Mirzaei-Paiaman et al., 2015). Different methods can be applied for interpreting the flow units and their corresponding petrophysical properties (Bagci et al., 2007; Banga et al., 2007; Schatz et al., 2007; Brigaud et al., 2014; Goda et al., 2014; Pyrcz et al., 2014; Rebelle, 2014). The amount and the type of information required by each method; however, varies depending on the data and the tools available (Jaya et al., 2005; Bagci et al., 2007; Askari et al., 2011; Rebelle, 2014; Tiab et al., 2015; Abdallah et al., 2016; Mirzaei-Paiaman et al., 2018). This may lead to different flow unit interpretation of the same reservoir. Several valuable re- 


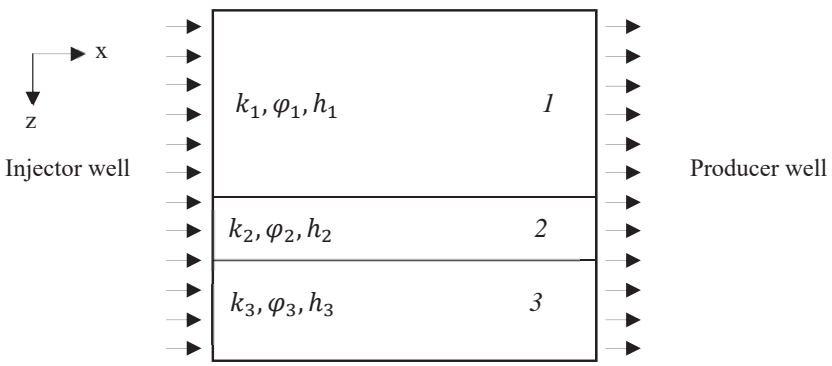

Fig. 1. Schematic of subdivision of a reservoir to different flow units (Stolz et al., 2003).

searches have been conducted on the evaluation of different flow unit identification techniques (Ali-Nandalal et al., 2003; Hamon, 2003; Frank et al., 2005; Guo et al., 2005; Salman et al., 2009; Hollis et al., 2010; Kale et al., 2010; Rebelle, 2014; Mirzaei-Paiaman et al., 2018). However, a comparative study that includes applications of different methods in reservoir description is lacking (Kadkhodaie-Ilkhchi et al., 2009; Izadi et al., 2013; Mirzaei-Paiaman et al., 2015; Chen et al., 2017).

\section{Hydraulic flow unit concept}

The concept of flow unit has been developed to integrate geological and petroleum engineering data which is defined as group of reservoir rocks with similar properties that effect fluid flow. Interpretation of flow units based on petrophysical properties, logs, and stratigraphy are routinely done for characterization of a reservoir that provides a better input into numerical flow simulation when compared to lithologic or depositional facies. The grouping of rocks based on their fundamental geological flow attributes is the basis of HFU classification (Al-Ajmi et al., 2000; Stolz et al., 2003).

As shown in Fig. 1, hydraulic flow units have the following characteristics (Rafiei, 2007):

1) A flow unit is a specific volume of reservoir, composed of one or more reservoir quality lithologies.

2) A flow unit is correlative and mappable at the interval scale.

3) A flow unit zonation is recognizable on wire-line log.

4) A flow unit may be in communication with other flow units.

HFU is characterized based on the following parameters and equations (Tiab et al., 2016):

$$
R Q I=\varphi_{n} \times F Z I
$$

where $R Q I$ is reservoir quality index; $\varphi_{n}$ is normalized porosity; and FZI is flow zone indicator:

$$
\begin{gathered}
F Z I=\frac{1}{\sqrt{F_{s}} \tau S_{g v}} \\
R Q I=0.0314 \sqrt{\frac{k}{\varphi_{e}}} \\
\varphi_{n}=\frac{\varphi_{e}}{1-\varphi_{e}}
\end{gathered}
$$

where $k$ is permeability in $\mu \mathrm{m}^{2}$ and $\varphi_{e}$ is effective porosity in fraction. The term $F_{s} \tau^{2}$ is known as the Kozeny constant, which is usually between 5 and 100 in most reservoir rock. The term $F_{s} \tau^{2} S_{g v}^{2}$ is a function of geological characteristics of porous media and varies with changes in pore geometry (Stolz et al., 2003).

Taking the logarithm of Eq. (1) on both sides yields:

$$
\log R Q I=\log \varphi_{n}+\log F Z I
$$

Eq. (5) yields a straight line on a log-log plot of $R Q I$ versus $\varphi_{n}$ with a unit slope. The intercept of this straight line at $\varphi_{n}=$ 1 is FZI. Samples with different FZI values will lie on other parallel lines. Samples that lie on the same straight line have similar pore throat characteristics and, therefore, constitute a flow unit.

FZI is a unique parameter that includes the geological attributes of the texture and mineralogy in the structure of distinct pore geometrical facies. In general, rocks containing authigenic pore lining, pore filling, and pore bridging clay as well as fine grained, poorly sorted sands tend to exhibit high surface area and high tortuosity, hence low FZI. In contrast, less shaly, coarse-grained, and well-sorted sand exhibit lower surface area, low shape factor, lower tortuosity, and higher FZI. Different depositional environments and diagenetic processes control the geometry of the reservoir and consequently the flow zone (Rafiei, 2007). The objective of this study is to determine the suitable HFU zonation technique for improving capillary pressure $\left(P_{c}\right)$ curve normalization on available log and core data of one well in one of the Iranian carbonate heavy oil reservoirs. The studied methods are gamma ray and density logs, FZI, Winland $r_{35}$ and capillary pressure curves. To do this, one of the Iranian carbonate oil reservoirs was selected. Collected well $\log$, and core data related to one of the wells in this reservoir were used as input data set.

\section{Reservoir properties}

The studied carbonate reservoir, which is located in southern Iran, is a part of giant oil field with about $90 \mathrm{~km}$ length and $16 \mathrm{~km}$ width in the surface. The reservoir rock consists of mainly dolomite with some interbedded shaly layers. The reservoir formations are considered for heavy oil and also highly fractured rocks.

\section{Case study}

The data set corresponds to one of the wells located in a carbonate heavy oil reservoir in the south part of Iran. Conventional well $\log$ information was available for the 90 m-deep well, in addition to petrophysical measurements on approximately 19 selected core plug samples. These data included: Gamma ray log, bulk density log, compensated neutron log, air permeability, helium core porosity and capillary pressure analysis.

Different hydraulic flow unit zonation methods were applied to the prepared data set in order to identify the flow units. After dividing the reservoir layer to different flow units, the Desouki's approach has been employed to normalize available 


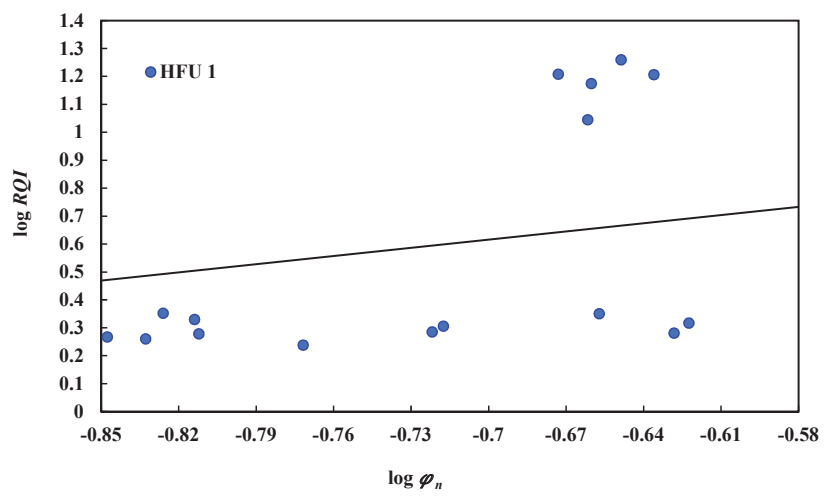

Fig. 2. Determination of $F Z I$ when reservoir is considered to be one big flow unit.

$P_{c}$ curves for each hydraulic flow units.

To have a better understanding of the HFU classification, a brief explanation of studied methods is explained as follows.

\subsection{Homogeneous reservoir with one flow unit}

In order to evaluate the effect of HFU zonation on improving normalization of $P_{c}$ curves, the reservoir is assumed to be one general big flow unit, then the results of HFU zonation from other techniques have been compared with this method.

The data source for this method consisted of core measurements of permeability and helium porosity from 19 core plug samples. In this very simple method, the entire depth of the well has been homogeneous, as if it was one big flow unit. Then $R Q I$ has been plotted versus $\mathrm{n}$ on $\log -\log$ scale. Intercept of the line with unit slop that crosses the $R Q I / \varphi_{n}$ points present the $F Z I$ value of the flow unit which is 21.98 $\mu \mathrm{m}$ (Fig. 2).

\subsection{Gamma ray and density $\log$}

Gamma ray logs measure natural radioactivity of the formations. In general, it can help differentiate shales (high radioactivity) from sands, carbonates, and anhydrites (low radioactivity) (Tiab et al., 2015). Also, the formation density $\log$ is a porosity $\log$ that measures electron density of a formation. It can be used to identify evaporate minerals, detect gas bearing zones, determine hydrocarbon density, and evaluate shaly-sand reservoirs and complex lithology (Stolz et al., 2003; Tiab et al., 2015).

Gamma ray log can be used as a simple tool to distinguish between sandstones and shales, and it establishes zones with different flow properties. By observing similarities in the gamma ray signature it is possible to further divide reservoir into different groups, which can be considered as flow units. The density $\log$ can be used to confirm the flow unit zonation and to calculate average porosity values for the depth intervals (Stolz et al., 2003).

In this method flow units are interpreted using the gamma ray (GR) $\log$, and the density $\log (\mathrm{DL})$. The applied method includes the following steps:

1) Zones with similar GR signature were grouped and interpreted as single flow units.

2) A flow unit number was assigned to each of these groups based on HFU definition (Fig. 3).

3) The density log was then used to confirm the zonation. To reach this goal, both gamma ray and density log were normalized and plotted versus depth (Fig. 4).

In this category total reservoir depth divided in to three flow units as illustrated in Figs. 3 and 4. It can be seen that the same hydraulic flow unit identified in different depth by both gamma ray and density logs. The result of GR can be integrated with other techniques to extrapolate results of them to un-cored intervals.

\subsection{Flow zone indicator}

The method for the flow unit zonation was developed using FZI concept. All samples with similar FZI values belong to the same flow unit because of the similarities in their pore throat attributes. Iterative multi-linear clustering regression (IMLR) technique is used by HFUA software to find the optimum number of flow units.

HFUA is a self developed software for clustering. Indeed, this software uses an iterative multi linear, regression algorithm to identify HFU clusters of a certain core sample. It loads an ASCII file of permeability and porosity data. Ones the calculation procedure is done, $R Q I$ is then plotted versus normalized porosity. All calculations are done by using visual basic programming. Data clustering is based on user decision by clicking on a desired point of the plotted figure. This makes the software to pass an optimized line through the data by considering the minimum sum of error. To minimize the impacts of outlier points, the data should be fitted using robust least squares regression. This is addressed by software using a robust Levenberg-Marquart (Bisquare weights) regression scheme. The scheme finds a curve that minimizes the absolute weight of sum squares, rather than the squared differences. Therefore, extreme values have minimum impact on the results.

The HFU classification process using core data requires the following steps:

1) Compute $R Q I$ and normalized porosity $\varphi_{n}$ from core information.

2) Plot $R Q I$ versus $\varphi_{n}$ in logarithmic space.

3) Use a reasonable initial guess of the intercept each straight-line equation, the mean $F Z I$ value of each HFU.

4) Assign core sample data to the nearest straight line.

5) Recalculate the intercept of each HFU using LevenbergMarquart regression equations.

6) Compare the new and old values of the intercept for every straight line. If the difference is within the acceptable tolerance, update intercept values and go to step 4).

7) The procedure above should be repeated until the optimal location of each straight line is found in which the error sum of squares is a minimum for the desired number of hydraulic flow units (Fig. 5).

To find the optimum number of flow units, sensitivity analysis has been conducted on different number of flow units. 


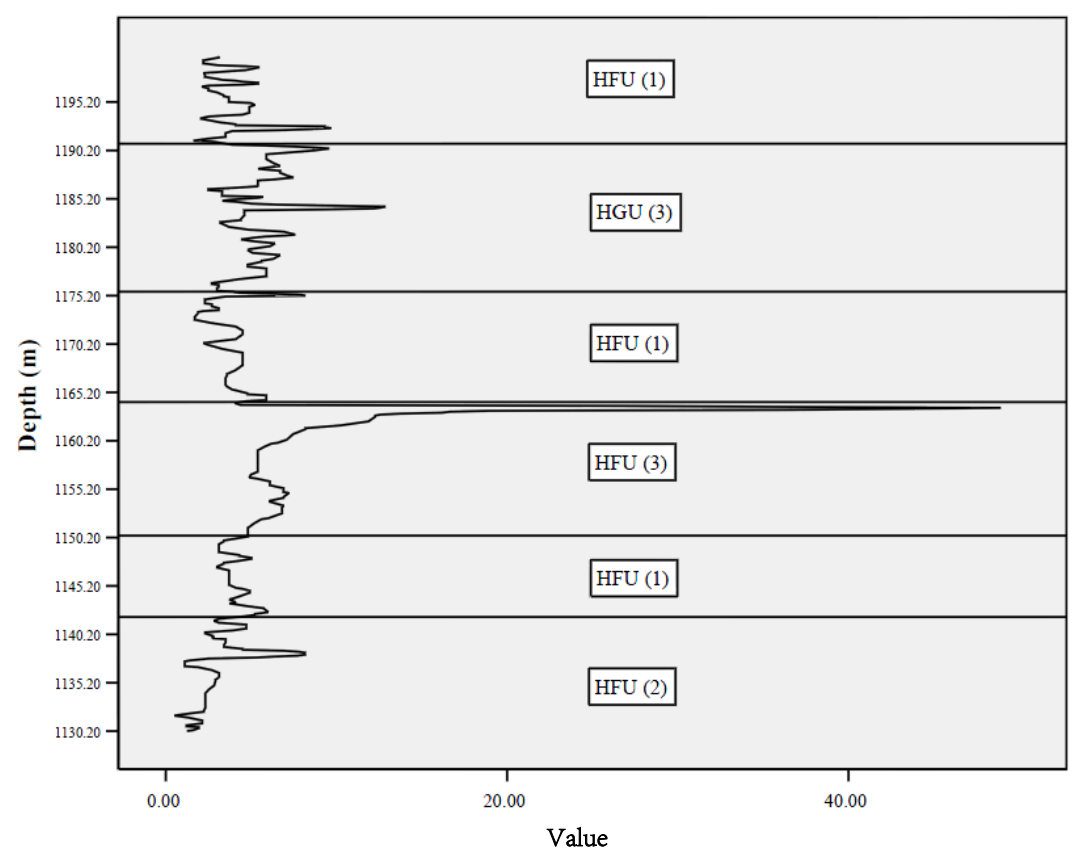

Fig. 3. Identification of flow units from gamma ray log.

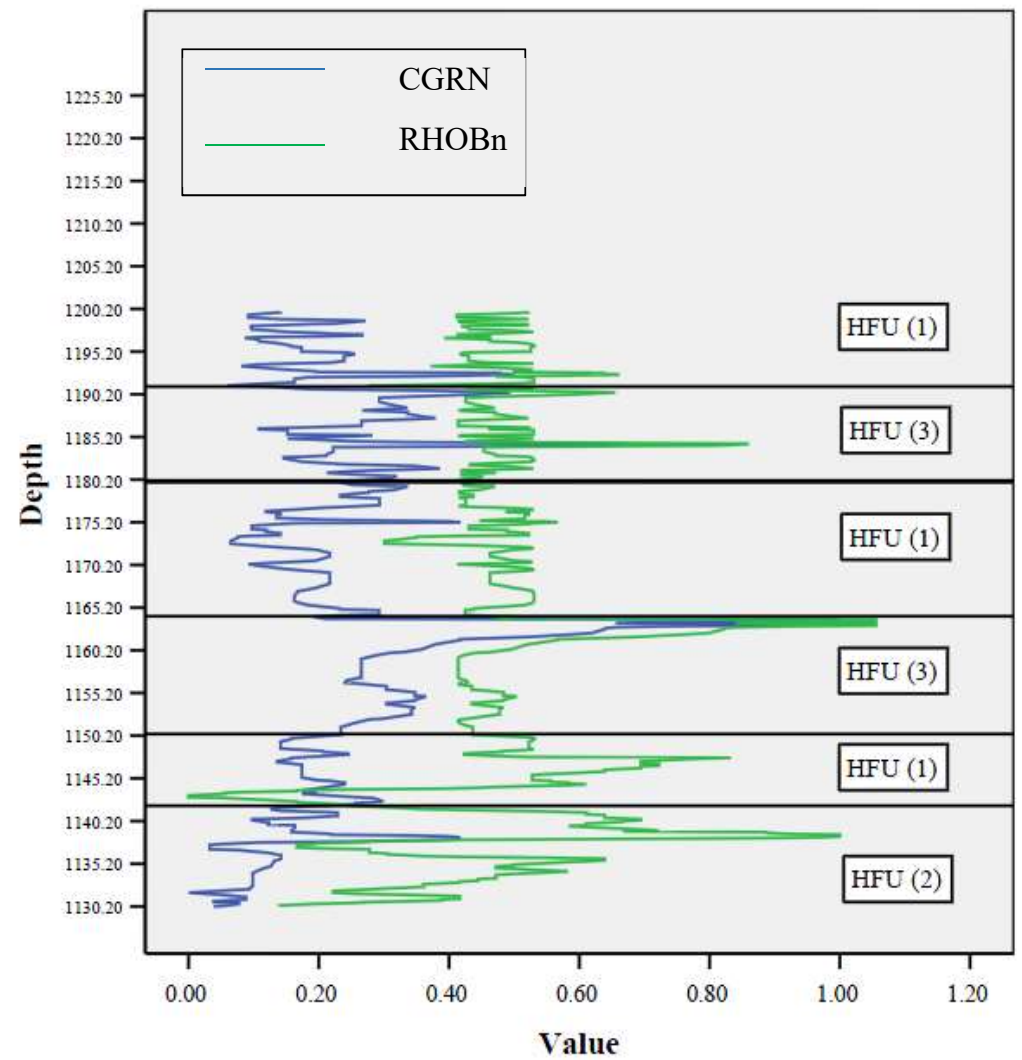

Fig. 4. Flow unit zonation using both gamma ray and density logs (CGRN means compensated gamma ray neutron; RHOBn means neutron density log). 


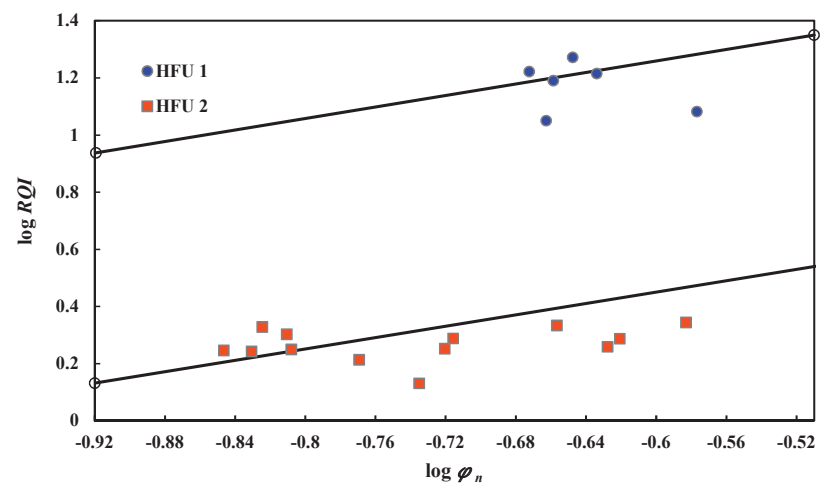

Fig. 5. Hydraulic flow unit identification based on FZI method.

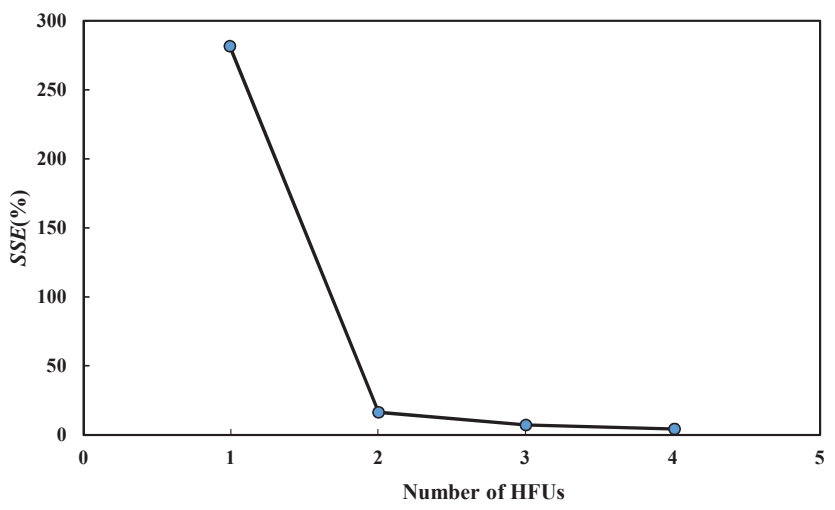

Fig. 6. Total SSE versus number of flow units.

Table 1. Distribution of each HFU with its correspondent FZI value.

\begin{tabular}{lll}
\hline HFU groups & $F Z I(\mu \mathrm{m})$ & Depth intervals $(\mathrm{m})$ \\
\hline HFU 1 & 12.23 & $1113.0-1125.0,1150.4-1200.0$ \\
HFU 2 & 78.02 & $1142.0-1150.4$ \\
\hline
\end{tabular}

Adding more HFUs should cause a reduction in the sum of square error $(S S E)$. However, as we continue to add more HFUs, we will reach a point where error reduction is getting smaller and smaller. The SSE in this case can be used as a criterion for determining when we have enough HFUs to describe the data. A plot of error sum square versus the number of HFUs is shown in Fig. 6. This clearly shows a declining $S S E$ curve with adding more HFUs until it gets to 2 where the SSE curve will be flat. This indicates that two HFUs are fair representations of the number of HFUs in the formation.

The distribution of these units in different depth and the FZI values are shown in Table 1.

\subsection{Winland's $r_{35}$}

Winland, H.D. (Aguilera, 2002; Mirzaei-Paiaman et al., 2018) used mercury injection capillary pressure curves and multiple regression analysis to develop an empirical equation. The proposed equation included porosity, air permeability, and the pore aperture corresponding to a mercury saturation of
$35 \%$ from over 300 sandstone and limestone samples. He ran regressions for other percentiles $(30,40$, and 50), but the best correlation (highest $\mathrm{R}^{2}$ ) was obtained for the 35 th percentile. The Winland's equation, which was used and published by Kolodzie (Jaya, 2005) is as follows:

$$
\log r_{35}=0.732+0.588 \log k-0.846 \log \varphi
$$

where $r_{35}$ is the pore aperture radius $(\mu \mathrm{m})$ corresponding to the 35 th percentile mercury saturation, $k$ is air permeability in $\mathrm{mD}$, and $\varphi$ is porosity in percentage.

According to Slotz et al. (2003), five petrophysical flow units with different reservoir performances can be distinguished by ranges of $r_{35}$, which are introduced in Table 2 . The steps included in this method can be summarized as follows:

1) The $r_{35}$ for each sample was calculated by Eq. (6).

2) A plot of $r_{35}$ versus sample number was drawn. The $r_{35}$ radii were classified into macro-porous, meso-porous, and micro-porous. The results are shown in Fig. 7.

3) The groups were interpreted as flow units.

4) Samples were assigned to their corresponding flow unit. Corresponding FZI values were calculated from plot of $R Q I$ versus $\varphi_{n}$ for each flow unit. Results are shown in Fig. 8.

5) These HFU definitions extrapolate to the entire depth of

Table 2. Flow unit classification by Winland $r_{35}$ method.

\begin{tabular}{ll}
\hline Group name & $r_{35}(\mu \mathrm{m})$ \\
\hline Mega-porous & $>10$ \\
Macro-porous & $2.5-10$ \\
Meso-porous & $0.5-2.5$ \\
Micro-porous & $0.2-0.5$ \\
Nano-porous & $<0.2$ \\
\hline
\end{tabular}

Table 3. Calculated FZI values for each HFU definition based on $r_{35}$.

\begin{tabular}{ll}
\hline HFU Groups & FZI \\
\hline HFU 1 & 11.22 \\
HFU 2 & 72.13 \\
HFU 3 & 17.13 \\
\hline
\end{tabular}

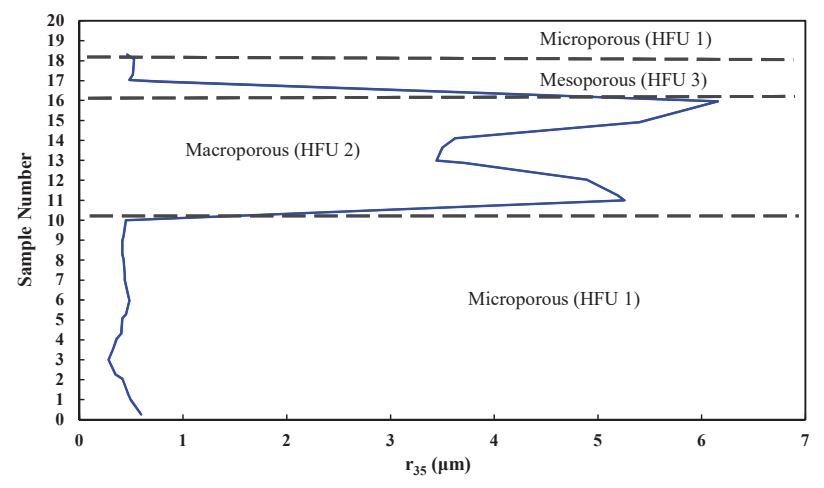

Fig. 7. Hydraulic flow unit classification based on $r_{35}$. 


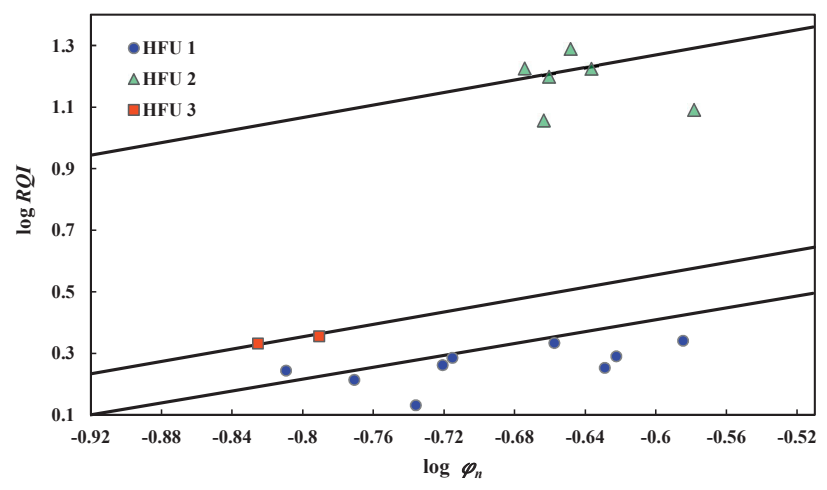

Fig. 8. Plot of $R Q I$ versus normalized porosity for HFUs identified by $r_{35}$ technique.

the reservoir based on GR and DL as discussed before.

Three hydraulic flow units have been defined based on $r_{35}$ model (Fig. 7). The FZI values for each unit are shown in Table 3 .

\subsection{Capillary pressure curves}

Knowing that capillary pressure should depend on the porosity, interfacial tension, and mean pore radius, Leverett defined the dimensionless function of water saturation, which he called $J$-function (Leverett, 1941). This function was originally formulated as follows:

$$
J\left(S_{w}\right)=\frac{P_{c}\left(S_{w}\right) \sqrt{\frac{k}{\varphi}}}{\sigma \cos \theta}
$$

where $P_{c}$ is capillary pressure (psia) at a saturation $S_{w}$ (fraction), $\sigma$ is the interfacial tension (dyne/cm), $k$ is permeability (mD), $\theta$ is wettability angle and $\varphi$ is porosity (fraction). In order to characterize the capillary pressure curves by contact angle, Swanson (Swanson, 1981) developed another parameter that can be used as single point method for comparing capillary pressure curves. He stated that the maximum curvature of the hyperbolic equivalent of a capillary pressure curve is found at the intersection of the hyperbola with a $45^{\circ}$ line passing through the origin of the hyperbolic axes. The ratio of the coordinates of this point, $\left(S_{b} / P_{c}\right)_{A, H g}$, has a maximum value at the apex of the hyperbola. According to Swanson, the capillary pressure at this point corresponds to the pore sizes that effectively interconnect the total major pore system that dominate fluid flow. Wells et al. (1985) presented alternative method for calculating the Swanson parameter. Swanson observed that a plot of $\left(S_{b} / P_{c}\right)^{1 / 2}$ versus $\log S_{b}$ (the bulk volume occupied by mercury) resulted in a well-defined minimum, which is a unique petrophysical parameter $\left(\psi_{H_{g}}\right)$ for a given sample (Swanson, 1981):

$$
\psi_{H g}=\left(\frac{P_{c}}{S_{b}}\right)^{\frac{1}{2}}
$$

This parameter is related to Swanson Parameter by (Swanson, 1981):

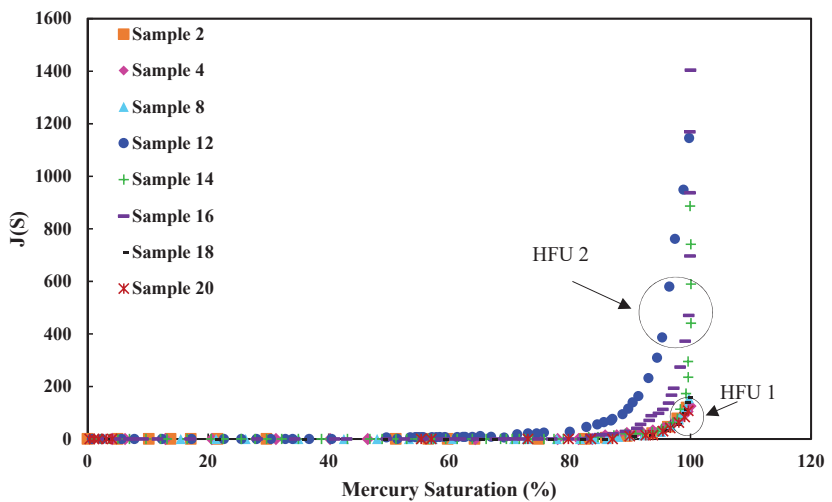

Fig. 9. Plot of $J$-function versus mercury saturation for different samples.

Table 4. Calculated values of $\psi_{H g}$ for each sample.

\begin{tabular}{lll}
\hline Samples & $\psi_{\mathrm{Hg}}$ & HFU groups \\
\hline 2 & 15.28 & HFU 1 \\
4 & 15.57 & HFU 1 \\
8 & 15.96 & HFU 1 \\
12 & 7.83 & HFU 2 \\
14 & 5.70 & HFU 2 \\
16 & 7.63 & HFU 2 \\
18 & 13.84 & HFU 3 \\
19 & 13.68 & HFU 3 \\
\hline
\end{tabular}

$$
\psi_{H g}=\left(\frac{P_{c}}{S_{b}}\right)_{A, H g}^{\frac{1}{2}}
$$

The data source for this was Specific Core Analysis Lab data, mercury injection data (10 capillary pressure curves), gamma ray, and density logs. The steps followed in this method are explained as follows:

1) The capillary pressure curves were normalized using the $J\left(\mathrm{~S}_{H g}\right)$-function.

2) The $J\left(\mathrm{~S}_{\mathrm{Hg}}\right)$-function was plotted as a function of mercury saturation $\left(\mathrm{S}_{\mathrm{Hg}}\right)$ in logarithmic scale. By visual inspection, the curves with similar shapes were grouped.

3) To interpret the flow units, both similarity in shape and location along the depth of the well were taken into account. Curves that were similar and located within a certain depth interval were considered to be a flow unit. Two flow units were defined as shown in Fig. 9.

4) To confirm this flow unit definition, the petrophysical parameter $\psi_{\mathrm{Hg}}$ of the samples were calculated. These values were compared to check that they were similar within the flow units. It was observed that the $\psi_{\mathrm{Hg}}$ values of samples in each flow units are in a certain range. The results are shown in Table 4.

5) The primary flow units were extrapolated to the un-cored depths of the well by using the gamma ray and the density logs.

The results of HFU classification by this method were the same as the one obtained previously by FZI model with the 
same $F Z I$ values for each flow unit.

After determining the HFUs, capillary pressure curves were normalized for each HFU using Desouky's approach (Desouky, 2003). The method requires the measurements of capillary pressure, irreducible water saturation, and routine core data such as permeability and porosity.

\section{Normalization of capillary pressure curves}

In order to evaluate the effect of flow unit classification on the capillary pressure normalization, $P_{c}$ curves for each flow unit were normalized using Desouky's method (Desouky, 2003). Desouky modified $J$-function to incorporates the effects of pore geometry (pore size distribution index $(\lambda)$ and $F Z I)$, lithology index $\left(J^{*}\right)$ and irreducible water saturation. Desouky's method generally accounts for simplification of the heterogeneity. From Eqs. (1) and (3) the term $\sqrt{k / \varphi}$ is given by:

$$
\sqrt{\frac{k}{\varphi}}=F Z I \times \varphi_{n}
$$

Desouky derived the following equation by substituting Eq. (10) into Eq. (7) (Desouky, 2003):

$$
J\left(S_{w}\right)=P_{c} \times F Z I \times \frac{\varphi_{n}}{\sigma \cos \theta}
$$

where $J\left(S_{w}\right)$ is Leverett $J$-function, $P_{c}$ is capillary pressure in $\mathrm{psi}, \sigma$ is interfacial tension in dynes/cm, $\theta$ is contact angle.

For capillary pressure data of a constant pore geometry (i.e., a fixed value of $F Z I$ ), the relationship between the values of $J\left(S_{w}\right)$ and normalized water saturation $\left(S_{w n}\right)$ is given by (Desouky, 2003; Tiab et al., 2015):

$$
J\left(S_{w}\right)=J^{*} \times S_{w n}^{\frac{-1}{\lambda}}
$$

where (Tiab et al., 2015):

$$
S_{w n}=\frac{S_{w}-S_{w i}}{1-S_{w r}}
$$

The term $J^{*}$ is known as the lithology index and its value equals to $J\left(S_{w}\right)$ when $S_{w n}=1$. The term $\lambda$ is the pore size

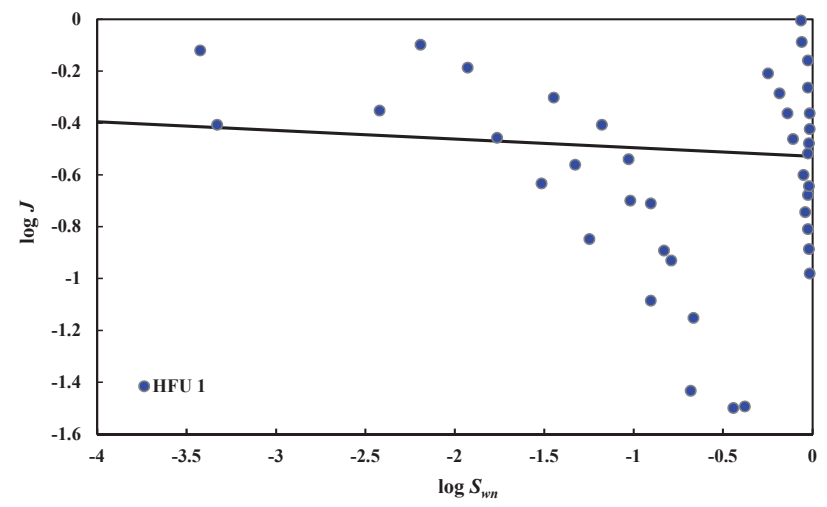

(a) distribution index, which is equal to the reciprocal of the slope.

Substituting Eq. (12) in Eq. (13) and re-arranging it, one obtains (Desouky, 2003):

$$
P_{c}=J^{*} \times S_{w n}^{\frac{-1}{\lambda}} \frac{\sigma \cos \theta}{F Z I \varphi_{n}}
$$

Eq. (14) is the normalized capillary pressure equation for each identified flow unit of a given reservoir.

Given the routine core data $(k$ and $\varphi$ ), capillary pressure data $\left(P_{c}-S_{w}\right)$, and irreducible water saturation $\left(S_{w r}\right)$, the following steps will be taken to normalize the capillary pressure curves for each flow units of different HFU classification as obtained in previous parts:

1) Capillary pressure data of each flow unit were identified. The capillary pressure data of each flow unit are corresponding to the core data of that unit.

2) Capillary pressure data and core data were used to calculate the values of $J$-function and normalized water saturation from Eqs. (10) and (12), respectively.

3) The values of $J$-function against normalized water saturation were plotted on log-log scale, and then $J^{*}$ and $\lambda$, for each flow unit were determined. Results for each HFU models are shown in Figs. 10(a), 11(a) and 12(a). The normalized $P_{c}$ curve equation for each unit was determined, using Eq. (13). The normalized capillary pressure curves are illustrated in Figs. 10(b), 11(b) and 12(b).

\section{Results and discussion}

\subsection{HFU classification}

Various flow units were identified by applying different HFU classification methods on available $\log$ and core data. FZI and capillary pressure methods resulted in two HFUs, while reservoir was divided into three flow units when GR/DL and Winland's $r_{35}$ were employed. Since pore size distribution index varies considerably through different flow units, it would play a key role in defining HFUs. Hence, a desirable method would be the one that is more sensitive to the pore geometry

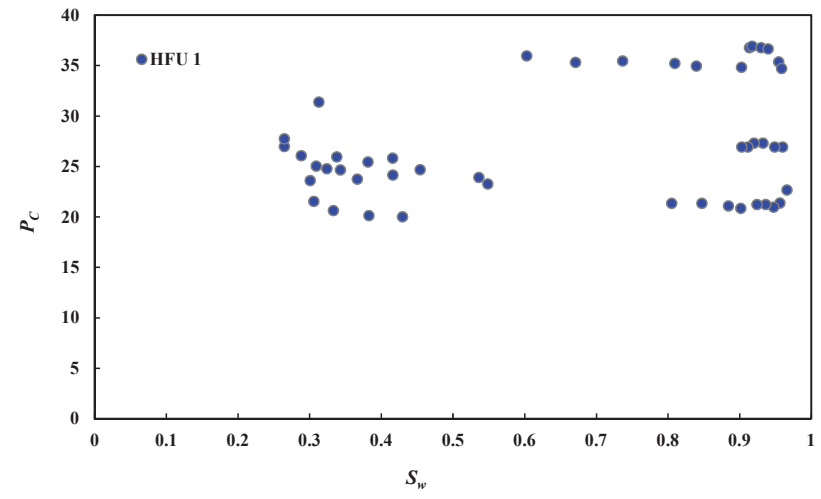

(b)

Fig. 10. (a) $J$-function versus normalized saturation when one flow unit is defined; (b) Normalized $P_{c}$ curve of the reservoir (one HFU model). 


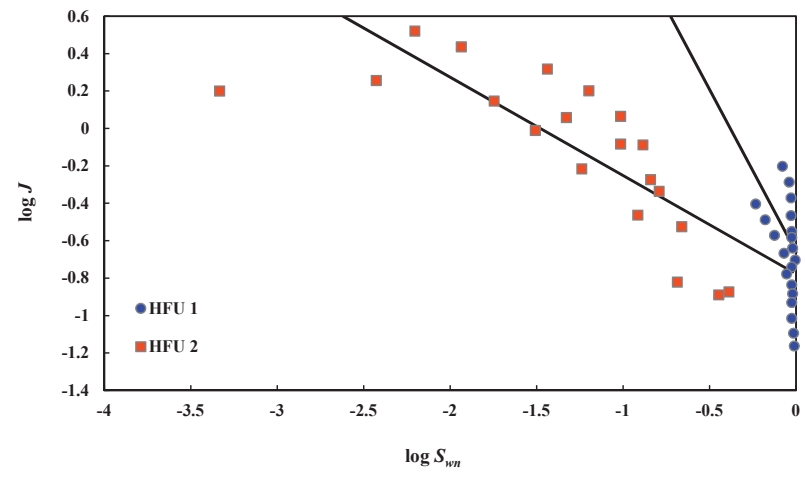

(a)

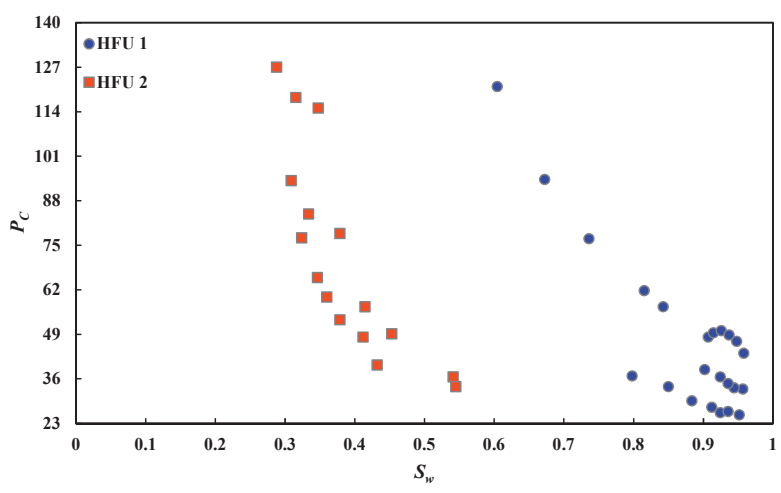

(b)

Fig. 11. (a) $J$-function versus normalized saturation when two flow unit is defined; (b) Normalized $P_{c}$ curve for all flow units (two HFU model).

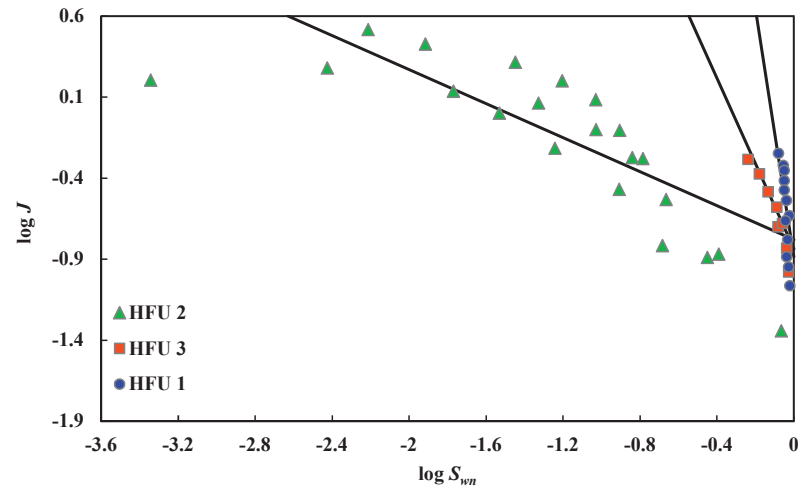

(a)

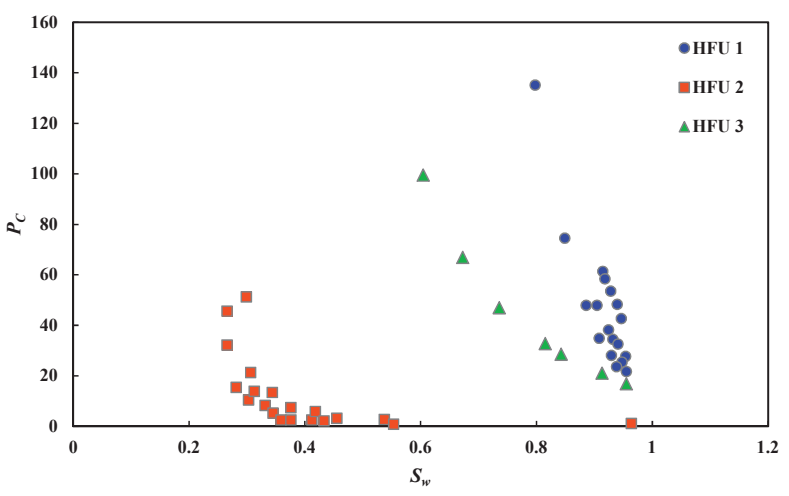

(b)

Fig. 12. (a) $J$-function versus normalized saturation when three flow unit is defined; (b) Normalized $P_{c}$ curve for all flow units (three HFU model).

Table 5. Summary of the results for each model.

\begin{tabular}{lllll}
\hline Models & HFUs & $F Z I$ & $J^{*}$ & $\lambda$ \\
\hline One HFU & HFU 1 & 21.98 & 0.3244 & 27.3219 \\
\multirow{4}{*}{ Two HFUs } & HFU 1 & 12.23 & 0.2149 & 0.58 \\
& HFU 2 & 72.13 & 0.1685 & 1.92 \\
& HFU 1 & 11.22 & 0.1203 & 0.1189 \\
Three HFUs & HFU 2 & 72.13 & 0.1685 & 1.92 \\
& HFU 3 & 17.13 & 0.1317 & 0.367 \\
\hline
\end{tabular}

of the rock. In this study, Winland's method is a more robust technique, as it divided the reservoir into three flow units. Although three HFUs can be also defined using GR and DL, this division is highly relying on visual accuracy, so it would be recommended to use more advanced clustering methods along with GR and DL. The results of HFU classification are summarized in Table 5.

\subsection{Normalizing $P_{c}$ curves}

An increase in the number of flow units reduces the total sum of square errors and causes the correlation coefficient $\left(\mathrm{R}^{2}\right)$
Table 6. Summary of total sum of square errors and correlation coefficients between measured $P_{c}$ and normalized one.

\begin{tabular}{lll}
\hline Models & Total SSE $(\%)$ & $\mathrm{R}^{2}$ \\
\hline One HFU & 8.67 & 0.245 \\
Two HFUs & 3.39 & 0.557 \\
Three HFUs & 2.46 & 0.741 \\
\hline
\end{tabular}

between measured values of capillary pressure in the lab and normalized values to go up Table 6, therefore, subdivision of the reservoir into hydraulic flow units significantly improve the normalization of $P_{c}$ curves. This is due to the fact that the capillary pressure curves are dependent upon the pore geometry and pore size distribution.

In order to have more accurate results, those models which are more sensitive to pore size distribution index should be used to define flow units. In this study the third method has higher accuracy compared to the other techniques, so that Winland's $r_{35}$ will be recommended to use for normalization of $P_{c}$ curves.

\section{Conclusions}


1) Different HFU techniques resulted in different $\mathrm{HFU}$ classification. This is because: (a) Employing different sources of data. (b)Application of different interpretation techniques: FZI was based on sensitivity analysis on number of HFUs and interpretation on reduction of SSE, Windland $r_{35}$ was a rigorous empirical equation, GR was based on visual interpretation and was more qualitative.

2) Pore size distribution index is an important parameter that change significantly between different flow units.

3) Those techniques that are more sensitive to this parameter were classified reservoir into more flow units.

4) Classification of reservoir into different flow units, improved normalization of capillary pressure curves.

\section{Acknowledgement}

We would like to thank Dr. Ramin Moghadasi and Ms. Atefeh Dargahi Zarandi for their help and support during this work.

Open Access This article is distributed under the terms and conditions of the Creative Commons Attribution (CC BY-NC-ND) license, which permits unrestricted use, distribution, and reproduction in any medium, provided the original work is properly cited.

\section{References}

Abdallah, S., Sid Ali, O., Benmalek, S. Rock type and permeability prediction using flow-zone indicator with an application to berkine basin (Algerian Sahara). Paper SEG-2016-13943527 Presented at 2016 SEG International Exposition and Annual Meeting, Dallas, Texas, 16-21 October, 2016.

Aguilera, R. Incorporating capillary pressure, pore throat aperture radii, height above free-water table, and winland r35 values on pickett plots. AAPG Bull. 2002, 86(4): 605624.

Al-Ajmi, F.A., Holditch, S.A. Permeability estimation using hydraulic flow units in a central arabia reservoir. Paper SPE 63254 Presented at SPE Annual Technical Conference and Exhibition, Dallas, Texas, 1-4 October, 2000.

Ali-Nandalal, J., Gunter, G. Characterising reservoir performance for the mahogany 20 gas sand based on petrophysical and rock typing methods. Paper SPE 81048 Presented at SPE Latin American and Caribbean Petroleum Engineering Conference, Port-of-Spain, Trinidad and Tobago. 27-30 April, 2003.

Amaefule, J.O., Altunbay, M., Tiab, D., et al. Enhanced reservoir description: Using core and log data to identify hydraulic (flow) units and predict permeability in uncored intervals/wells. Paper SPE 26436 Presented at SPE Annual Technical Conference and Exhibition, Houston, Texas, 3-6 October, 1993.

Askari, A.A., Behrouz, T. A fully integrated method for dynamic rock type characterization development in one of iranian off-shore oil reservoir. J. Chem. Pet. Eng. 2011, 45(2): 83-96.

Bagci, A.S., Akbas, C.Y. Permeability estimation using hydraulic flow units in carbonate reservoirs. Paper
SPE 107263 Presented at Rocky Mountain Oil \& Gas Technology Symposium, Denver, Colorado, USA, 16-18 April, 2007.

Banga, R., Tyagi, A.K. Identification of flow units in carbonate reservoir using karstification theory. Paper SPWLA-MERS-2007-O Presented at SPWLA Middle East Regional Symposium, Abu Dhabi, UAE, 15-19 April, 2007.

Brigaud, B., Vincent, B., Durlet, C., et al. Characterization and origin of permeability-porosity heterogeneity in shallowmarine carbonates: From core scale to 3D reservoir dimension (Middle Jurassic, Paris Basin, France). Mar. Pet. Geol. 2014, 57: 631-651.

Chang, L., Liqiang, S., Anjiang, S. The application of the reservoir heterogeneity evaluate method with microresistivity image $\log$ in $\mathrm{FC}$ formation of $\mathrm{G}$ region in northeastern Sichuan. Prog. Geophys. 2015, 30(2): 725732.

Chen, X., Zhou, Y. Applications of digital core analysis and hydraulic flow units in petrophysical characterization. Adv. Geo-Energy Res. 2017, 1(1): 18-30.

Davies, D., Vessell, R. Identification and distribution of hydraulic flow units in a heterogeneous carbonate reservoir: North Robertson Unit, West Texas. Paper SPE 35183 Presented at Permian Basin Oil and Gas Recovery Conference, Midland, Texas, 27-29 March, 1996.

Desouky, S. A new method for normalization of capillary pressure curves. Oil Gas Sci. Technol. 2003, 58(5): 551556.

Frank, S., Narayanan, R., Hansen, P., et al. Carbonate rock typing using nmr data: A case study from al shaheen field, offshore qatar. Paper IPTC-10889-MS Presented at International Petroleum Technology Conference, Doha, Qatar, 21-23 November, 2005.

Goda, T., Sato, K. History matching with iterative Latin hypercube samplings and parameterization of reservoir heterogeneity. J. Pet. Sci. Eng. 2014, 114: 61-73.

Guo, G., Diaz, M., Paz, F., et al. Rock typing as an effective tool for permeability and water-saturation modeling: A case study in a clastic reservoir in the Oriente basin. Paper SPE 97033 Presented at SPE Annual Technical Conference and Exhibition, Dallas, Texas, 9-12 October, 2005.

Hamon, G. Two-phase flow rock-typing: Another perspective. Paper SPE 84035 Presented at SPE Annual Technical Confe, Denver, Colorado rence and Exhibition, 5-8 October, 2003.

Hingerl, F.F., Yang, F., Pini, R., et al. Characterization of heterogeneity in the Heletz sandstone from core to pore scale and quantification of its impact on multi-phase flow. Int. J. Greenhouse Gas Control 2016, 48: 69-83.

Hollis, C., Vahrenkamp, V., Tull, S., et al. Pore system characterisation in heterogeneous carbonates: An alternative approach to widely-used rock-typing methodologies. Mar. Pet. Geol. 2010, 27(4): 772-793.

Izadi, M., Ghalambor, A. A new approach in permeability and hydraulic flow unit determination. Paper SPE 151576 Presented at SPE International Symposium and 
Exhibition on Formation Damage Control, Lafayette, Louisiana, USA, 15-17 February, 2012.

Izadi, M., Ghalambor, A. New approach in permeability and hydraulic-flow-unit determination. SPE. Reserv. Eval. Eng. 2013, 16(3): 257-264.

Jaya, I., Sudaryanto, A., Widarsono, B. Permeability prediction using pore throat and rock fabric: A model from indonesian reservoirs. Paper SPE 93363 Presented at SPE Asia Pacific Oil and Gas Conference and Exhibition, Jakarta, Indonesia, 5-7 April, 2005.

Kadkhodaie-Ilkhchi, A., Amini, A. A fuzzy logic approach to estimating hydraulic flow units from well log data: A case study from the Ahwaz Oilfield, South Iran. J. Pet. Geol. 2009, 32(1): 67-78.

Kale, S., Rai, C., Sondergeld, C. Rock typing in gas shales. Paper SPE 134539 Presented at SPE Annual Technical Conference and Exhibition, Florence, Italy, 19-22 September, 2010.

Kaydani, H., Mohebbi, A., Baghaie, A. Permeability prediction based on reservoir zonation by a hybrid neural genetic algorithm in one of the Iranian heterogeneous oil reservoirs. J. Pet. Sci. Eng. 2011, 78(2): 497-504.

Leverett, M. Capillary behavior in porous solids. Trans. AIME 1941, 142(1): 152-169.

Mirzaei-Paiaman, A., Ostadhassan, M., Rezaee, R., et al. A new approach in petrophysical rock typing. J. Pet. Sci. Eng. 2018, 166: 445-464.

Mirzaei-Paiaman, A., Saboorian-Jooybari, H., Pourafshary, P. Improved method to identify hydraulic flow units for reservoir characterization. Energy Technol. 2015, 3(7): 726-733.

Ngo, V.T., Lu, V., Nguyen, M.H., et al. A comparison of permeability prediction methods using core analysis data. Paper SPE 175650 Presented at SPE Reservoir Characterisation and Simulation Conference and Exhibition, Abu Dhabi, UAE, 14-16 September, 2015.

Nooruddin, H.A., Hossain, M.E. Modified Kozeny-Carmen correlation for enhanced hydraulic flow unit characterization. J. Pet. Sci. Eng. 2011, 80(1): 107-115.

Pittman, E.D. Relationship of porosity and permeability to various parameters derived from mercury injectioncapillary pressure curves for sandstone. AAPG Bull. 1992, 76(2): 191-198.

Pyrcz, M.J., Deutsch, C.V. Geostatistical Reservoir Modeling. New York, USA, Oxford University Press, 2014.
Rabiller, P. Combining porosimetry and purcell permeability modeling to calibrate FZI and define a dynamic permeability cut off. Paper SCA2017-081 Presented at International Symposium of the Society of Core Analysis, Vienna, Austria, 27-30 August, 2017.

Rafiei, Y. An extensive study on effect of different hydraulic flow unit classification on normalizing of capillary pressure curves and permeability estimation of one of Iranian heavy oil reservoir. Ahwaz, Petroleum University of Technology, 2007.

Rebelle, M. Rock-typing in carbonates: A critical review of clustering methods. Paper SPE 171759 Presented at $\mathrm{Abu}$ Dhabi International Petroleum Exhibition and Conference, Abu Dhabi, UAE, 10-13 November, 2014.

Salman, S.M., Bellah, S. Rock typing: An integrated reservoir characterization tool to construct a robust geological model in Abu Dhabi carbonate oil field. Paper SPE 125498 Presented at SPE/EAGE Reservoir Characterization \& Simulation Conference, Abu Dhabi, UAE, 19-21 October, 2009.

Schatz, B.M., Heinemann, Z. Flow-based determination of hydraulic units. Paper SPE 107158 Presented at EUROPEC/EAGE Conference and Exhibition, London, UK, 11-14 June, 2007.

Soto, B., Garcia, J., Torres, F., et al. Permeability prediction using hydraulic flow units and hybrid soft computing systems. Paper SPE 71455 Presented at SPE Annual Technical Conference and Exhibition, New Orleans, Louisiana, 30 September-3 October, 2001.

Stolz, A.K., Graves, R.M. Sensitivity study of flow unit definition by use of reservoir simulation. Paper SPE 84277 Presented at SPE annual technical conference and exhibition, Denver, Colorado, 5-8 October, 2003.

Swanson, B. A simple correlation between permeabilities and mercury capillary pressures. J. Pet. Technol. 1981, 33(12): 2498-2504.

Tiab, D., Donaldson, E.C. Petrophysics: Theory and Practice of Measuring Reservoir Rock and Fluid Transport Properties. Oxford, UK, Gulf Professional Publishing, 2015.

Wells, J., Amaefule, J. Capillary pressure and permeability relationships in tight gas sands. Paper SPE 13879 Presented at SPE/DOE Low Permeability Gas Reservoirs Symposium, Denver, Colorado, 19-22 March, 1985. 